\title{
The life course: challenges and opportunities for public health research
}

\author{
Matthias Richter • David Blane
}

Published online: 4 December 2012

(C) Swiss School of Public Health 2012

While life course approaches in the social sciences have a long tradition (Elder and Giele 2009; Heinz et al. 2009), it was not until the 1990s that a life course perspective was also introduced to the analysis of health and longevity. With origins in research on health inequalities, the hypothesis of biological programming and the availability of national longitudinal data, life course epidemiology has been investigating the long-term effects of biological, physical and social exposures on health and chronic disease risk during gestation, childhood, adolescence, young adulthood and later adult life and across the generations (Kuh et al. 2003; Blane et al. 2007; Ben-Shlomo 2007). In this context, a wealth of innovative findings were gained by integrating determinants and mechanisms acting earlier in life to the explanation of health and health inequalities in adulthood. Life course influences are increasingly seen to hold the key to a better understanding of disease aetiology and the existence of social inequalities in health.

Present-day life course research in the field of epidemiology and public health faces several challenges and

This article is part of the special issue "Life course influences on health and health inequalities: moving towards a Public Health perspective".

M. Richter $(\bowtie)$

Institute of Medical Sociology (IMS), Medical Faculty, Martin Luther University Halle-Wittenberg, Magdeburger Str 8, 06112 Halle (Saale), Germany

e-mail: m.richter@medizin.uni-halle.de

D. Blane

Imperial College London, London, UK

D. Blane

ESRC International Centre for Life Course Studies in Society and Health (ICLS), London, UK opportunities, which we address in this special issue of the International Journal of Public Health (issue 58-1, 2013). Life course thinking is interdisciplinary in nature. However, life course research on health and health inequalities was largely dominated by epidemiological studies, which paid relatively little attention to other disciplines also relevant for public health. The significant benefits potentially available from bringing together the separate traditions, for example, in demography, epidemiology and sociology have not been fully utilized. With this in mind, the special issue on life course research explicitly covers contributions from several disciplines dealing with health: Mortelmans and Vannieuwenhuyze and Leopold and Engelhardt illustrate the contribution of sociology, Siegel et al. of econometrics, and Neels et al. of demography.

Another challenge related to the disciplinary exchange is the further development of conceptual models that elucidate the risk and protective factors at each life stage as well as the underlying mechanisms that link them together across one or more generations. Much life course research involves both social and biological factors, although often their treatment lacks social and biological plausibility. In the special issue, we publish a paper, which attempts to overcome these problems in relation to cancer. Using evidence from epidemiology, neurobiology and biological sciences, Kelly-Irving et al. show that adverse childhood experiences may set up the organism's susceptibility to the future development of cancer; an effect that can be mediated by subsequent environmental exposures across the individual's subsequent life course trajectory.

So far, life course research on health and health inequalities has been largely informed by birth cohort studies in the UK but increasing evidence comes from longitudinal studies in other countries. The wealth of new studies coming on-stream worldwide offers great scientific 
possibilities. We feature among others a new study from Norway, but equally could have chosen new studies from China, France, Italy or Japan. The paper by Naess and Hoff introduces the census-based "Norwegian Family Based Life Course" study, with over 5 million people one of the largest follow-up studies worldwide; Cirera et al. present findings from the Spanish EPIC cohort based on more than 40,000 participants, Mann et al. introduce the Newcastle Thousand Families study while Larson and Halfon use the Alameda County study.

Finally, the international proliferation of longitudinal studies offers great opportunities for international comparative research which, in turn, challenges us to think about how to aggregate countries for research purposes. The contribution from Harding et al. focusses on retirement age and used welfare state theory to compare the pattern of mortality by work status around retirement ages in Finland, Italy, Wales and England.

Overall, the life course perceptive represents a fruitful opportunity to advance our understanding of health and health inequalities and has been an emerging area of research. Next to the conceptual and empirical challenges addressed in this special issue, few studies deal with the impact of life course research for public health policy and practice. Thus, while the special issue signals the possibility and importance of an interdisciplinary exchange and has the promise for developing a broader life course approach, an important task of the next years will be to underpin the vast number of empirical findings theoretically and to increasingly transfer the findings into strategies to promote health and to tackle the increasing health inequalities across the globe.

\section{References}

Ben-Shlomo Y (2007) Rising to the challenges and opportunities of life course epidemiology. Int J Epidemiol 36:481-483

Blane D, Netuveli G, Stone J (2007) The development of life course epidemiology. Rev Epidemiol Sante Publique 55:31-38

Elder GH Jr, Giele JZ (2009) The craft of life course research. The Guilford Press, New York

Heinz W, Huinink J, Weymann A (2009) Life course reader: individuals and society across time. Campus, Frankfurt/M

Kuh D, Ben-Shlomo Y, Lynch J, Hallqvist J, Power C (2003) Life course epidemiology. J Epidemiol Community Health 57:778-783 